\title{
CONQUISTAS E DESAFIOS PARA A FORMAÇÃo CONTINUADA DOCENTE A PaRTiR do Plano Municipal de educação em Ponta Porã/MS APROVADO NO ANO DE 2015
}

\author{
ACHIEVEMENTS AND CHALLENGES FOR CONTINUED TEACHING EDUCATION FROM THE \\ MUNICIPAL EDUCATION PLAN IN PONTA PORÃ/MS APPROVED IN THE YEAR OF 2015 \\ LOGROS Y DESAFÍOS PARA LA EDUCACIÓN CONTÍNUA DOCENTE A PARTIR DEL PLAN DE \\ EDUCACIÓN MUNICIPAL EN PONTA PORÃ/MS APROBADO EN EL AÑO DE 2015
}

\section{Silvano Artur Busch \\ Vergutz \\ (iD) 9 \\ Mestrando Profissional em Educação (PROFEDUC/UEMS). \\ Coordenador Pedagógico no município de Ponta Porã/MS. \\ Discente no Mestrado Profissional em Educação \\ (PROFEDUC/UEMS) \\ vergutzsilvano_11@hotmail.com}

\section{Marsiel Pacífico}

\section{iD 9}

Doutor em Educação (UFSCar)

Professor Adjunto na Universidade Estadual de Mato Grosso do Sul (UEMS)

Docente Permanente no Mestrado

Profissional em Educação

(PROFEDUC/UEMS)

marsiellp@gmail.com

\section{Antonio Sales \\ (iD) 9}

Doutor em (UFMS)

Professor Titular na Universidade

Anhanguera (UNIDERP)

Professor Sênior no Mestrado

Profissional em Educação

(PROFEDUC/UEMS)

profesales@hotmail.com

\begin{abstract}
Resumo
O artigo apresenta uma análise com objetivo de abordar o Plano Municipal de Educação em Ponta Porã/MS (PME) mediante a apresentação de pontos importantes da legislação aplicada à formação docente que atuará nas séries iniciais do ensino fundamental e verificar se o mesmo está alinhado com os Planos Nacional e Estadual de Educação, enfatizando a influência da LDB 9.394/96 e das Diretrizes Curriculares Nacionais. A metodologia utilizada é a revisão de literatura com ênfase documental sobre as relações existentes entre esses norteadores da educação em conjunto com as ações realizadas pela administração pública municipal. A pesquisa destaca as conquistas e desafios nas políticas públicas e compreende a importância da formação continuada, ainda que esta permaneça aquém do que se é necessário para que ocorra uma transformação expressiva nos métodos de ensino e se obtenha o avanço desejado na educação, ferramenta de grande importância para alcançar uma educação pública de qualidade.

Palavras-chave: Formação Continuada. Plano Municipal de Educação. Ponta Porã.
\end{abstract}

Recebido em: 16 de junho de 2021.

Aprovado em: 31 de agosto de 2021.

Como citar esse artigo (ABNT):

VERGUTZ, Silvano Artur Busch; PACÍFICO, Marsiel; SALES, Antonio. Conquistas e desafios para a formação continuada docente a partir do plano municipal de educação em Ponta Porã/MS aprovado no ano de 2015. Revista Prática Docente, v. 6, n. 2, e074, 2021. http://doi.org/10.23926/RPD.2021.v6.n2.e074.id1272 


\section{Abstract}

The article presents an analysis to approach the Municipal Education Plan in Ponta Porã/MS (PME) through the presentation of important points of the legislation applied to teacher education that will act in the initial grades of elementary school and verify if it is aligned with the National and State Education Plans, emphasizing the influence of LDB 9.394/96, of the National Curriculum Guidelines. The methodology used was a literature review with a documental emphasis on the relations between these education guides in conjunction with the actions carried out by the public administration in the city. The research seeks to highlight the achievements and challenges in public policies and understand the importance of continued education, even though they remain below what is necessary, for a significant transformation in teaching methods to take place and reach the desired advance in education, a tool that carries great importance in achieving quality public education.

Keywords: Continued Education. Municipal Education Plan. Ponta Porã.

\section{Resumen}

El artículo presenta un análisis con el objetivo de abordar el Plan de Educación Municipal en Ponta Porã/MS (PME) mediante la presentación de puntos importantes de la legislación aplicada a la formación docente que actuará en los primeros grados de la escuela primaria y comprobar si está en consonancia con los Planes de Educación Nacionales y Estatales, enfatizando la influencia de la LDB 9.394/96, de las Directrices del Plan de Estudios Nacional. La metodología utilizada fue una revisión de literatura con énfasis documental en las relaciones existentes entre estas guías educativas junto con las acciones realizadas por la administración pública en la ciudad. La investigación busca resaltar los logros y desafíos en las políticas públicas y comprender la importancia de la educación continua, aunque se mantengan por debajo de lo necesario, para que se produzca una transformación expresiva en los métodos de enseñanza y lograr el avance deseado en educación, herramienta de gran importancia para alcanzar una educación pública de calidad.

Palabras clave: Educación Continua. Plan de Educación Municipal. Ponta Porã. 


\section{INTRODUÇÃ̃o}

A formação inicial de professores subsidia o trabalho do docente, mas não é suficiente. É nesse contexto que a formação continuada surge como uma alternativa de formação complementar. Assim, compreende-se que a formação continuada de professores se processa de forma essencial na atividade docente, sendo fundamental na busca da eficaz prática educacional pedagógica. Nessa concepção, Prada (2007) observou que alguns municípios não oferecem a formação continuada, mesmo sendo amparado em suas legislações. O autor explica que:

[...] no Brasil, embora a formação continuada de professores seja garantida pela própria $\mathrm{LDB} / 96$, observamos como o tempo para ela é contrário ao período de trabalho - nos fins de semana ou nas férias e, ainda, em muitos casos, os custos são por conta dos próprios profissionais, constituindo-se, mais em uma obrigação que em um direito (PRADA, 2007, p. 121).

Partindo desse pressuposto, vale ressaltar que a formação continuada de professores da Educação Básica está amparada legalmente na Lei de Diretrizes e Bases da Educação Nacional do Brasil (LDB) 9.394/96, pelo Plano Nacional de Educação do Brasil (PNE) 13.005/2014 e o Plano Estadual de Educação de Mato Grosso do Sul (PEE) 8.657/2014. Diante disso, o artigo apresenta uma análise com objetivo de verificar a oferta de cursos de formação continuada com o intuito de colaborar com esse aperfeiçoamento profissional em Ponta Porã/MS, fundamentada nos dados do Plano Municipal de Educação de Ponta Porã (PME) que estão sendo traçadas pelas políticas atuais (2014 - 2024), documentando todas as ações.

Contudo, o PME de 2005 de Ponta Porã, instituído em 17 de dezembro de 2008 pela Lei 3.633 (Revogada pela Lei ${ }^{\circ} 4.100$, de 2 de junho de 2015), revela grandes problemas com a formação continuada de docentes; a inexistência de políticas voltadas para a formação continuada de professores que atuam na educação infantil, anos iniciais e finais do ensino fundamental, visando a melhoria da qualidade de aprendizagem de todos os componentes. Apresenta, ainda, a inexistência de políticas de formação de pessoal escolar no geral, bem como o descumprimento da Lei 10.639, de 9 de janeiro de 2003, que deveria estar alinhado ao PNE 10.172/2001 que foi institucionalizado por meio do Decreto 6.094/2007 (AMORIM, 2011).

Diante disso, este artigo justifica-se, pois a partir dele será possível realizar uma reflexão sobre as reformas educacionais e quais são seus reflexos no processo de formação de professores, nos conhecimentos essenciais para a formação dos profissionais da educação, tendo em vista que são os agentes de transformação da educação. 
Nos Artigos 9, 10 e 11 da LDB 9.394/96, fica disposto sobre o Plano Nacional de Educação (BRASIL, 2017):

Art. $9^{\circ}$. A União incumbir-se-á de:

I - elaborar o Plano Nacional de Educação, em colaboração com os Estados, o Distrito Federal e os Municípios;

Art. 10. Os Estados incumbir-se-ão de:

III - elaborar e executar políticas e planos educacionais, em consonância com as diretrizes e planos nacionais de educação, integrando e coordenando as suas ações e as dos seus Municípios;

Art. 11. Os Municípios incumbir-se-ão de:

I - organizar, manter e desenvolver os órgãos e instituições oficiais dos seus sistemas de ensino, integrando-os às políticas e planos educacionais da União e dos Estados (BRASIL, 2017, p.11-12).

O Ministério da Educação (MEC) se constitui como um importante referencial para a elaboração de novas diretrizes e políticas educacionais em suas orientações para elaboração do PMEde Ponta Porã (MEC; SASE, 2014), e esclarece que:

A Constituição Federal, a Lei de Diretrizes e Bases da Educação Nacional e o novo PNE, que agora é lei, estipulam que as metas nacionais, especialmente aquelas que dizem respeito às etapas obrigatórias da educação nacional, são responsabilidades conjuntas da União, dos estados, do Distrito Federal e dos municípios (MEC; SASE, 2014, p. 6).

Para o desenvolvimento da pesquisa buscou-se compreender a proposta curricular para a formação continuada e o documento norteador do PME de Ponta Porã/MS aprovado sob a Lei $\mathrm{n}^{\mathrm{o}}$ 4.100, de 2 de junho de 2015 (PONTA PORÃ, 2015), conforme os compromissos e necessidades educacionais municipais que são definidos no PNE 13.005/2014 e no PEE 8.657/2014, previstas e em consonância com a Constituição Federal do Brasil de 1988. Outro documento que fez parte da pesquisa documental é a LDB 9.394/1996, e como aponta Saviani (2011, p. 2), também é chamada de "carta magna da educação" quando se quer acentuar a sua importância. No Artigo 14, inciso II, diz que os sistemas de ensino definirão as normas da gestão democrática do ensino público na educação básica:

Art. 14. Os sistemas de ensino definirão as normas da gestão democrática do ensino público na educação básica, de acordo com as suas peculiaridades e conforme os seguintes princípios:

I - participação dos profissionais da educação na elaboração do projeto pedagógico da escola;

II - participação das comunidades escolar e local em conselhos escolares ou equivalentes (BRASIL, 1996, p. 6-7).

O referido documento enfatiza a importância do estudo contínuo, pois somente o conhecimento adquirido em anos escolares não supre a necessidade educacional. Nesse sentido, 
aponta a formação continuada como um constante processo de transformação para o fazer pedagógico.

A partir do Relatório de Avaliação de Ponta Porã coloca que esse foi um trabalho em conjunto com a Comissão de Monitoramento e Avaliação, por meio da Secretaria Municipal de Educação (SEME), apontando que a formação inicial não dá conta de suprir todas as necessidades cotidianas e que se faz necessário evidenciar novas oportunidades de contextualizar novas circunstâncias e ressignificar a atuação do professor, proporcionando a qualidade em todos os sentidos que dizem respeito ao espaço escolar (IMBERNÓN, 2010).

Objetivou-se compreender a proposta curricular para a formação continuada, e foram encontradas na conjuntura do PME (PONTA PORÃ, 2015) evidências que apontam para a responsabilidade de alinhar as prerrogativas e necessidades educacionais municipais ao que determina a LDBLei ${ }^{\circ}$ 9.394/96, no artigo 62:

Art. 62. A formação de docentes para atuar na educação básica far-se-á em nível superior, em curso de licenciatura plena, admitida, como formação mínima para o exercício do magistério na educação infantil e nos cinco primeiros anos do ensino fundamental, a oferecida em nível médio, na modalidade normal. (Redação dada pela lei $\mathrm{n}^{\circ}$ 13.415, de 2017).

$\S 1^{\circ}$ A União, o Distrito Federal, os Estados e os Municípios, em regime de colaboração, deverão promover a formação inicial, a continuada e a capacitação dos profissionais de magistério. (Incluído pela Lei no 12.056, de 2009).

$\S 2^{\circ} \mathrm{A}$ formação continuada e a capacitação dos profissionais de magistério poderão utilizar recursos e tecnologias de educação a distância (Incluído pela Lei no ${ }^{0} 12.056$, de 2009) (BRASIL, 1996).

As ações previstas neste documento estão em consonância com a Constituição Federal do Brasil, de 1988, na LDB de 1996 e no PNE - uma lei que está em vigência desde 25 de junho de 2014 e estabelece diretrizes, metas e estratégias para os próximos dez anos da educação brasileira e enfatiza que o mesmo se constitui como um importante referencial para a elaboração de novas diretrizes e políticas.

Saviani (2011, p. 3) considera a importância do Plano afirmando que: “O PNE é importante pois tem caráter global que abrange todos os aspectos que dizem respeito à organização da educação nacional, e caráter operacional, já que define ações traduzidas em metas a serem atingidas em prazos determinados [...]."

Dessa forma, definiu-se como objetivo deste trabalho de investigação, analisar o Plano Municipal de Educação em Ponta Porã/MS (PME) mediante a comparação com a legislação de maior amplitude como os Planos Nacional e Estadual de Educação, levando em conta a formação continuada de professores que atuam nos anos inciais da educação básica. 


\section{Metodologia}

Este artigo utilizou de uma abordagem de pesquisa qualitativa em função do discurso da exploração documental como um processo de percepção da realidade social e por meio da avaliação de diferentes tipos de arquivos "a fim de uma compreensão mais apurada do problema que está sendo estudado", como descrito por Ludke e André (1986, p.12). De acordo com Bogdan e Biklen (1994, p.13), "a pesquisa qualitativa envolve a obtenção de dados descritivos, obtidos no contato direto do pesquisador com a situação estudada, enfatiza mais o processo do que o produto e se preocupa em retratar a perspectiva dos participantes."

Para o desenvolvimento deste artigo, metodologicamente realizou-se uma pesquisa em documentos cedidos pela SEME, onde está contido o Plano de Formação Continuada, o qual foi analisado, e plano este que norteia as diretrizes municipais, com o intuito de verificar como a formação continuada é tratada no PME em Ponta Porã.

A pesquisa documental consiste em entender que:

Documentação é toda forma de registro e sistematização de dados, informações, colocando-os em condições de análise por parte do pesquisador. Pode ser tomada em três sentidos fundamentais: Como técnica de coleta, de organização e conservação de documentos; como ciência que elabora critérios para a coleta; contexto da realização de uma pesquisa, é a técnica de identificação, exploração, levantamento de documentos fontes do objeto pesquisado e registro das informações retiradas nessas fontes e que serão utilizadas no desenvolvimento do trabalho (SEVERINO, 2007, p.124).

A partir dessa perspectiva, este artigo tem por objetivo apresentar uma análise documental e articulada a uma abordagem bibliográfica com ênfase na formação continuada no município de Ponta Porã/MS, considerando que o PME (2014 - 2024) poderá ser limitado ou potencializado pelo PEE. Dito isso, pressupõe o envolvimento das três esferas de gestão (federal, estadual e municipal) e de representações dos diversos segmentos da sociedade, mas não deixa de conferir peso e importância ao papel dos dirigentes municipais.

Nesse sentido, destaca-se ainda a demanda dos professores por cursos de formação continuada de modo que nos remete abordar, ainda que sucintamente, essa prática no município de Ponta Porã/MS, considerando a relação dessa demanda com a oferta de formação continuada pelo município, fundamentado com a LDB, na qual a ideia de formação continuada entrou em evidência no Brasil principalmente em 1996, em que busca, na orientação de uma política para o magistério, a valorização do profissional da educação escolar. Partindo desse pressuposto, em consonância com a LDB, Imbernón (2016) afirma:

A profissão docente se desenvolve profissionalmente mediante diversos fatores: o salário, a demanda do mercado de trabalho, o clima de trabalho nas instituições nos 
quais se exerce, a promoção dentro da profissão, as estruturas hierárquicas, a carreira docente etc.; é claro, mediante a formação inicial e permanente que essa pessoa realiza ao longo de sua vida profissional (IMBERNÓN, 2016, p.185).

A Formação Continuada requer políticas sólidas e estar concordante com os objetivos primários dos parâmetros e direções educativas, posicionando o docente de forma estratégica, de modo que esse tenha em suas práxis instrumentos e metodologias hábeis e efetivas, primordiais no alcance de uma educação libertadora.

\title{
3 FUNDAMENTAÇÃo TEÓRICA
}

\subsection{FORMAÇÃO CONTINUADA: CONCEPÇÕES E SEUS DESAFIOS}

$\mathrm{O}$ artigo segue registrando a presença de um discurso que tem sustentado a crescente importância atribuída à formação continuada de professores, projetos e ações que visam a melhoria da qualidade dos sistemas de ensino e que devem estar alinhados com a realidade escolar brasileira, promovendo uma educação acessível, universal e de qualidade que estão assegurados na Constituição Federal Brasileira de 1988, na LDB de 1996, e nos Planos Nacional e Estadual de Educação.

Corroborando com os documentos supracitados, Imbernón (2011) aponta que é preciso considerar a heterogeneidade que caracteriza a vida cotidiana de nossas escolas e ressituar o profissional para aumentar-lhe a consideração do status social:

\begin{abstract}
A formação permanente se caracteriza por estar fundamentada no futuro em diversos pilares ou princípios: aprender continuamente; relacionar os conhecimentos derivados da socialização comum com novas informações em um processo coerente de formação. A partir da prática do professor, realizar um processo de prática teórica; aprender em um ambiente formativo de colaboração e de interação social: compartilhar problemas, fracassos e sucessos com os colegas; elaborar projetos de trabalho conjunto e vinculá-los à formação mediante estratégias de pesquisa ação (IMBERNÓN, 2011, p. 73).
\end{abstract}

Adotar essa prática de formação continuada de professores é muito relevante para o ensino nos tempos atuais em virtude das transformações sociais e da velocidade do desenvolvimento tecnológico, pois se amplia o conhecimento, leva-o a novas reflexões, a solução de problemas, mantém o professor atualizado, comprometido, aprendendo e ensinando, e leva-o a autoavaliação, fazendo com que se sinta parte de um contexto em que está inserido.

Conforme Saviani (2010) é necessária uma nova interpretação de formação de professores que contemple a continuidade de estudos para que a materialidade da ação educativa ocorra de forma que a teoria se confunda com a prática. É evidente que a formação continuada de professores necessita de compromisso político dos profissionais da educação, 
assumindo a prática docente com vistas à transformação social, de acordo com a base teórica constante nas diretrizes educacionais.

A formação continuada certamente é qualidade que deve estar presente nos planos públicos, assim como na própria essência dos agentes educativos (professores, coordenadores, pesquisadores do tema, entre outros). Diante das dificuldades recorrentes da prática profissional do professor, percebe-se a necessidade de continuar os estudos e buscar a promoção de um profissional satisfeito, eficiente e sustentável. Nesse âmbito, entende-se que:

A satisfação está associada aos seguintes fatores: uma identidade com a carreira e o trabalho[...], a eficiência profissional envolve uma formação inicial e continuada acessível, sólida, versátil, de qualidade específica e articulada as demandas profissionais, formação continuada periódica, planejada e articulada ao trabalho [...] e sustentabilidade profissional envolve criar condições para atrair novos profissionais e fidelizar os que já atuam[...] (PONTA PORÃ, 2015, p. 122).

A LDB 9.394/96, em seus artigos 61 e 62-A, prevê a formação e a valorização de todos os profissionais envolvidos na Educação:

Art. 61 - prevê professores, pedagogos e funcionários como profissionais da educação. [...]

Art. 62-A - dispõe sobre a formação inicial dos integrantes da Categoria III (funcionários da educação) em nível médio e superior (tecnológico, graduação plena e pós-graduação), garantindo no parágrafo único a formação continuada nos dois níveis (BRASIL, 1996, p.23).

Conforme previsto no Art. 42 citado na LDB, está direcionada ao modo em que o governo se situa sobre tal prática, que envolve leis, normas e diretrizes sobre como deve ocorrer o processo formativo dos professores no âmbito da carreira docente e a sua continuidade.

É inegável que a Lei $n^{\circ}$ 9.394/96 veio resgatar uma das maiores dívidas sociais que o país tem para com o sistema educacional e os anseios nacionais que clamam por prosperidade econômica e justiça social. A partir dessa concepção, de acordo com o PNE, para que a melhoria da educação se concretize no âmbito municipal, parte-se da premissa de que o professor deve estar aparelhado de forma adequada às práxis pedagógicas, tendo em posse os conhecimentos e saberes sobre o processo de ensino-aprendizagem como uma função libertadora. Concomitantemente com a LDB, e alinhados aos PNE e ao PEE, Imbernón (2010) aponta:

O conhecimento profissional consolidado mediante a formação permanente apoia-se [sic] tanto na aquisição de conhecimentos teóricos e de competências de processamento da informação, análise e reflexão crítica em, sobre e durante a ação, o diagnóstico, a decisão racional, a avaliação de processos e a reformulação de projetos (IMBERNÓN, 2010, p.75).

Nesse sentido, aponta a formação continuada como um constante processo de transformação para o fazer pedagógico e, por intermédio das leis supracitadas, o município de 
Ponta Porã visa garantir a todos os profissionais da educação básica a formação continuada em sua área de atuação, alinhada às metas dos Planos Nacional e Estadual de Educação. Assim, destacam-se as seguintes diretrizes:

Busca no médio prazo, de totalidade dos profissionais do magistério, com licenciatura especifica na Etapa da Educação Básica e/ou no componente curricular [...]; Organização de carreira com níveis de progressão e promoção por tempo de serviço e formação continuada, com reconhecimento salarial [...]. Formação inicial e continuada dos profissionais, com incentivo financeiro das redes para afastamento remunerado [...] (PONTA PORÃ, 2015, p. 123).

A mesma Lei $n^{\circ}$ 9.394/96 estabelece nos artigos 61 e 62 que o sistema dispõe sobre a necessidade de valorizar os profissionais da Educação e propiciar formação continuada no intuito de assegurar-lhes o aperfeiçoamento profissional continuado. No que tange à formação continuada, o desenvolvimento profissional e a atualização desses professores, faz-se necessário aprofundamento em temáticas educacionais e embasamento teórico que seja refletido na práxis escolar.

O município de Ponta Porã ressalta no PME que a formação inicial e continuada deve propiciar, dentre outros benefícios:

Sólida formação teórica nos conteúdos específicos a serem ensinados na Educação Básica, bem como nos especificamente pedagógicos; ampla formação cultural, prática docente como foco formativo, contato com a realidade escolar desde o início até o final do curso, integrando a teoria à prática pedagógica, pesquisa como princípio formativo, domínio das novas tecnologias da comunicação e da informação e acesso a elas, visando a sua integração à prática do magistério [...] (PONTA PORÃ, 2015, p. 123).

Diante do exposto, colocar os professores nesta conjuntura de sempre estarem atualizados sobre novas metodologias, avanços sobre os significados de aprendizagem e analisando as metas conquistadas pela cidade, ficam evidentes as contribuições que esse paradigma (Formação Continuada) tem no seio educativo.

Assim, será considerado que a Formação Continuada, a partir da definição adotada por Imbernón (2011, p.78) "representa uma reflexão prática e teórica sobre o próprio exercício profissional mediante a compreensão e a intervenção sobre a realidade". Por isso a escola é o espaço onde, de fato, o professor constrói sua formação. Dito isso, Libâneo (2004) afirma:

Uma formação permanente, que se prolonga por toda a vida, torna-se crucial numa profissão que lida com a transmissão einternalização de saberes e com a formação humana, numa época em que se renovam os currículos, introduzem-se novas tecnologias, acentuam-se os problemas sociais e econômicos, modificam-se os modos de viver e de aprender, reconhece-se a diversidade social e cultural dos alunos (LIBÂNEO, 2004, p. 227). 
O foco no âmbito municipal é de grande importância para a realização das metas e objetivos que estão sendo traçados pelas políticas atuais, pois é no município que a educação acontece na prática e que será justamente nele o ponto de partida para o levantamento de dados sobre a situação das prioridades locais e para o embasamento do PME.

\title{
3.2. A FORMAÇÃO CONTINUADA E O PME: ALGUMAS REFLEXÕES
}

De acordo com Freire (1991, p. 589) "ninguém nasce educador ou marcado para ser educador. A gente se faz educador, a gente se forma como educador, permanentemente, na prática e na reflexão da prática”. Diante desse contexto, garantir a Formação Continuada dos professores certamente agrega efeitos positivos para o docente.

Assim sendo, vale ressaltar a Meta 5 do PME que explica sobre as ações em Formação Continuada:

\begin{abstract}
Outra ação realizada pela instituição foi a Formação Continuada em Serviço para os professores alfabetizadores da Rede Municipal, com base nas necessidades observadas a partir das avaliações diagnósticas. O objetivo era subsidiar os docentes com novas estratégias de ensino, a partir da apresentação de novos referenciais teóricos e práticos, para os profissionais da educação. Além dos professores, os coordenadores também participaram de um ciclo de Formação Continuada objetivando a melhoraria [sic] do ensino e atendimento dos estudantes do Ciclo de Alfabetização, pois compreendemos que o coordenador tem um papel fundamental na construção de ambientes e práticas educativas ricas e geradoras de aprendizagens para todos que convivem na escola. Entre os anos de 2018 e 2019, também ocorreram várias Formações Continuadas em Regime de Colaboração com a Rede Estadual de Ensino, dentre as formações mencionamos o estudo do Currículo de Referência do Mato Grosso do Sul objetivando a implementação da Base Nacional Curricular Comum (BNCC) na rede estadual e municipal de educação (PONTA PORÃ, 2019, p.25).
\end{abstract}

A formação continuada certamente é qualidade que deve estar presente nos planos públicos, assim como na própria essência dos agentes educativos (professores, coordenadores, pesquisadores do tema, entre outros). Nessa mesma linha, a Meta 7 ainda explica:

Fomentar a qualidade da Educação Básica em todas as etapas e modalidades, com melhoria do fluxo escolar e da aprendizagem de modo a atingir as seguintes médias nacionais para o IDEB: 6,0 nos anos iniciais do Ensino Fundamental; 5,5 nos anos finais do Ensino Fundamental [...] (PONTA PORÃ, 2019, p. 27).

Com relação ao impacto da qualidade de ensino nos indicadores em conjunto com as ações de melhoria dos índices, o indicador 7A, juntamente com o relatório, explicam a necessidade de se observar uma formação continuada de todos os agentes educativos para a melhoria dos índices e, consequentemente, alcance dos objetivos. O Quadro 1 ilustra os índices educativos avaliados pelo IDEB na cidade de Ponta Porã. 
Quadro 1 - Média IDEB

\begin{tabular}{|c|c|c|c|c|}
\hline Indicador 7a & \multicolumn{3}{|c|}{ Média do IDEB nos anos inicias do ensino fundamental } \\
\hline \multirow{2}{*}{$\begin{array}{c}\text { Meta prevista para o } \\
\text { período }\end{array}$} & \multirow{2}{*}{$\begin{array}{c}\text { Dado } \\
\text { oficial }\end{array}$} & $\begin{array}{c}\text { Meta alcançada no } \\
\text { período }\end{array}$ & $\begin{array}{c}\text { Meta projetada para o } \\
\text { período }\end{array}$ & Fonte do indicador \\
\cline { 3 - 5 } & ofician & $2015: 5,7$ & 4,7 & IDEB \\
\cline { 3 - 5 } & & $2017: 5,8$ & 5,0 & IDEB \\
\hline
\end{tabular}

Fonte: Ponta Porã (2019, p.28).

Conforme mostra o Quadro 1, há uma superação da cidade referente as metas estabelecidas para os períodos, tanto no ano de 2015 como em 2017, a administração mostrou que existiu saldo positivo para com os objetivos. De acordo com dados do Ponta Porã (2019, p. 25), isso também é explicado devido ao:

Ciclo de Formação Continuada objetivando a melhoraria [sic] do ensino e atendimento dos estudantes do Ciclo de Alfabetização, pois compreendemos que o coordenador tem um papel fundamental na construção de ambientes e práticas educativas geradoras de aprendizagens $[\ldots]$ ".

A LDB, no decorrer do seu texto, veio contemplar a essência de sua natureza intrínseca, que é o seu teor social como parâmetro indicador dos objetivos e metas a serem alcançados nesse âmbito em especial. Na mesma premissa, a Formação Continuada, conforme Imbernón (2011, p.78), "representa uma reflexão prática e teórica sobre o próprio exercício profissional mediante a compreensão e a intervenção sobre a realidade". O professor em sua profissão pode assumir uma importante função social, bem como desenvolver uma cultura que possa ocorrer pelos processos da formação continuada.

Analisando os dados do indicador 15-A, entende-se que até 2019 a proporção de docências da educação infantil com professores cuja formação superior está adequada à área de conhecimento que lecionam refere-se a 97,83\%, ou seja, a meta está praticamente cumprida, considerando que o prazo final é até 2024. E o indicador 15-B evidencia que a proporção de docências dos anos iniciais do Ensino Fundamental com professores cuja formação superior está adequada à área de conhecimento que lecionam segue o mesmo padrão, pois 99,71\% dos professores dessa etapa possuem formação superior adequada à área de conhecimento, ou seja, todos os docentes possuem níveis de graduações compatíveis com suas funções acadêmicas (PONTA PORÃ, 2019, p.41).

Sobre a Lei no 9.394/96 é necessário destacar limitações em seu bojo textual, sendo que a mesma não se constitui, apesar de todos os seus avanços e inovações em matéria educacional, em um diploma legal ideal que venha efetivamente a resolver todas as problemáticas educacionais brasileiras. 
Em síntese, observou-se que, em escala municipal, destacam-se a necessidade da capacitação e formação continuada para o professor, contudo, apesar da oferta de alguns cursos, nota-se que nem todos os profissionais são atendidos em Ponta Porã/MS, sendo, no entanto, omissa no que diz respeito a estabelecer idêntica competência relativamente aos Municípios.

Além disso, existem modalidades de ensino que vêm depois da graduação, que estão em consonância com as metas e diretrizes educacionais, como por exemplo, a meta 16 do PNE:

Formar, em nível de pós-graduação, 50\% dos professores da Educação Básica, até o último ano de vigência deste PNE, e garantir a todos dos profissionais da Educação Básica formação continuada em sua área de atuação, considerando as necessidades, demandas e contextualizações dos sistemas de ensino (BRASIL, 2014, p. 27).

Assim, as reformas na educação como um todo, e para a formação de professores em especial, estão materializadas nos documentos que legitimam a educação nacional. Dentre estes, a LDB 9.394/96 dedica os artigos 61 a 65 ao Título VI - Dos Profissionais da Educação, trazendo mudanças importantes no contexto da formação dos profissionais da educação, com destaque para o parágrafo único do Art. 61:

A formação dos profissionais da educação, de modo a atender às especificidades do exercício de suas atividades, bem como aos objetivos das diferentes etapas e modalidades da educação básica, terá como fundamentos:

I - a presença de sólida formação básica, que propicie o conhecimento dos fundamentos científicos e sociais de suas competências de trabalho;

II - a associação entre teorias e práticas, mediante estágios supervisionados e capacitação em serviço;

III - o aproveitamento da formação e experiências anteriores, em instituições de ensino e em outras atividades (BRASIL, 1996, p. 42).

É importante mencionar que, de acordo com o artigo supracitado, o município elaborou seu PME em consonância com os Planos Nacional e Estadual de Educação, com adequações e estratégias, em que a SEME de Ponta Porã define que a formação continuada de professores se define em diversas concepções, como:

Cursos de especialização, programas de aperfeiçoamento do magistério, cursos à distância. A partir da formação continuada, os professores podem ser capazes de incorporar a prática de aperfeiçoamento no seu cotidiano, pois, desperta-se neles um aperfeiçoamento que fará com que tentem algo novo em sua prática docente (PONTA PORÃ, 2015, p. 128).

Sendo assim, a formação docente deve estar aparelhada a exigência legal do PNE, também colocado no bojo da Meta 16 do PME, em suas metas de ações para educação, que explica:

Formar, em nível de pós-graduação, 60\% dos (as) professores (as) da Educação Básica, até o último ano de PEE, e garantir a todos os profissionais da Educação 
Básica, formação continuada em sua área de atuação, considerando as necessidades, demandas e contextualização dos sistemas de ensino (PONTA PORÃ, 2015, p. 121).

Em síntese, a partir dessa análise, foi observado que a lei, tanto na escala nacional com a LDB como no PME, destaca a necessidade da capacitação e formação continuada para o professor, contudo, apesar da oferta de alguns cursos, nota-se que nem todos os profissionais são atendidos.

Tendo como base esses argumentos, a cidade de Ponta Porã ao longo dos anos implementou programas de formação continuada para a melhoria da qualidade de ensino, que é ilustrada nos Quadros 2 e 3, referente a proporção de docentes com pós-graduação como algo crescente ao longo dos anos.

Quadro 2 - Proporção de formação dos docentes

\begin{tabular}{|c|c|c|c|}
\hline \multirow{2}{*}{ Indicador 16A } & \multicolumn{2}{c|}{$\begin{array}{c}\text { Proporção de docência com professores que possuem pós-graduação } \\
\text { compatível com a área de conhecimento que lecionam na educação básica }\end{array}$} \\
\hline $\begin{array}{c}\text { Meta prevista para o } \\
\text { período }\end{array}$ & \multicolumn{2}{|c|}{ Meta alcançada no período } & \multicolumn{2}{c|}{ Fonte do indicador } \\
\hline \multirow{2}{*}{-} & \multirow{2}{*}{ Dado oficial } & $2016: 45,1 \%$ & \\
& & $2017: 44,9 \%$ & INEP: Censo da E \\
& & $2019:$ & Básica 2016-2018 \\
\cline { 2 - 4 } & Dado municipal & $00,00 \%$ & - \\
\hline
\end{tabular}

Fonte: Ponta Porã (2019, p.42).

Quadro 3 - Formação continuada compatível por área

\begin{tabular}{|c|c|c|c|}
\hline \multirow{2}{*}{ Indicador 16B } & \multicolumn{2}{c|}{$\begin{array}{c}\text { Proporção de docência com professores que possuem formação continuada } \\
\text { compatível com a área de conhecimento que lecionam na educação básica }\end{array}$} \\
\hline $\begin{array}{c}\text { Meta prevista para o } \\
\text { período }\end{array}$ & \multicolumn{2}{|c|}{ Meta alcançada no período } & Fonte do indicador \\
\hline \multirow{2}{*}{-} & Dado oficial & $\begin{array}{c}2018: 73,77 \% \\
2019:\end{array}$ & $\begin{array}{c}\text { INEP: Censo da E. } \\
\text { Básica 2017 - 2018 }\end{array}$ \\
\cline { 2 - 4 } & Dado municipal & $00,00 \%$ & - \\
\hline
\end{tabular}

Fonte: Ponta Porã (2019, p.43).

Garantir a Formação Continuada dos professores certamente agrega efeitos positivos tanto para o docente como em um quadro geral educativo da cidade, que ainda elucida que:

Sobre a garantia a todos (as) os (as) profissionais da Educação Básica, formação continuada em sua área de atuação, considerando as necessidades, demandas e contextualizações dos sistemas de ensino, nota-se que até o ano de 2018, 73,77\% dos professores da educação básica possuíam a formação continuada em sua área, indicando um avanço positivo para o alcance da meta. Para atingir esse indicador o município tem ofertado anualmente cursos de formação continuada aos professores da educação básica e cursos de educação à distância por meio das IES, porém até o momento, não há dados oficiais que contabilizem tais ações para fins de uma análise mais detalhada da meta, para o ano de 2019 não houve dados (PONTA PORÃ, 2019, p.43). 
A partir dos estudos sobre alguns documentos foram evidenciadas divergências entre algumas concepções teóricas abordadas, como a desvalorização salarial empurrando os professores para a busca de alternativas que lhes assegurem uma renda capaz de garantir o sustento de suas necessidades básicas, por isso é comum que muitos recorram à ampliação da jornada, acumulando assim dois ou mais períodos de trabalho.

Assim, segundo o Decreto n ${ }^{\circ}$ 9.005, de 14 de março de 2017 (revogado pelo Decreto $\mathrm{n}^{\mathrm{o}}$ 10.195, de 30 de dezembro de 2019), Art. 32, no inciso VI, compete ao MEC apoiar a formação inicial e continuada dos profissionais da educação, a estruturação de suas carreiras e remuneração e as relações democráticas de trabalho no âmbito da educação (BRASIL, 2017). Nessa conjuntura, Ponta Porã/MS destaca os seguintes pontos frágeis que merecem atenção na formulação das políticas necessárias para sua superação:

Baixa valorização dos profissionais da Educação; Insuficiência na organização orçamentária para a área de Educação [...]; Cursos insuficientes para profissionais da Educação, tanto do magistério e administrativo, resultando na elevação do número de convocados e contratados (PONTA PORÃ, 2015, p. 126).

Assim, especificamente a Meta 17, que trata da valorização dos profissionais do magistério das redes públicas de educação básica, de forma a equiparar seu rendimento médio ao dos demais profissionais com escolaridade equivalente, até o final do sexto ano de vigência desse PME, tendo em vista que essa meta está no bojo sobre a qualidade da educação na cidade, como as melhorias nas condições de trabalho e salarial, entram para tal paradigma.

No entanto, devido à ausência de dados não foi possível realizar uma análise da relação percentual entre o rendimento bruto médio mensal dos profissionais do magistério das redes públicas de todas as esferas mencionadas. Nesse contexto, foi possível analisar somente o rendimento bruto dos profissionais da educação básica da rede municipal e de profissionais de outras áreas da mesma rede. Diante disso, vale ressaltar que foi realizado uma análise dos rendimentos dos profissionais do magistério do município conforme o cálculo fornecido pelo Relatório de Avaliação do PME, que foi 258,38\% entre os anos de 2018 e 2019, segundo o relatório (PONTA PORÃ, 2019).

Sobre planos de carreira dos profissionais do magistério da Educação Básica no sistema de ensino municipal e estadual, é colocado na Meta 18, que explica:

\footnotetext{
Assegurar, no prazo de 2 anos, a existência de Planos de Carreira para os (as) profissionais da educação básica e superior pública de todos os sistemas de ensino e, para o plano de Carreira dos (as) profissionais da educação básica pública, tomar como referência o piso salarial nacional profissional, definido em lei federal, nos termos do inciso VIII do art. 206 da Constituição Federal (PONTA PORÃ, 2019, p.44).
} 
Quanto à aplicação do porcentual do valor da Lei do Piso Nacional, foi mencionado que no ano de 2018 a Rede Municipal de Ensino de Ponta Porã recebeu um reajuste do piso salarial, o valor correspondente a 6,70\%, o equivalente à $\mathrm{R} \$ 2.395,27$ (para professores que possuem Magistério Nível Médio) e o Ministério da Educação definiu o reajuste de 6,81\% para esse mesmo ano, o que corresponde ao valor de R \$2.455,30 (PONTA PORÃ, 2019).

Em 2019, o Ministério da Educação definiu o reajuste de 4,17\% para o piso nacional, o que corresponde a $\mathrm{R} \$ 2.557,74$ e a Rede Municipal de Ensino de Ponta Porã também reajustou esse mesmo valor $(4,17 \%)$ para a Rede Municipal de Ensino, o que equivale à $R \$ 2.495,15$ para os professores que trabalham 40 horas e possuem o magistério nível médio (PONTA PORÃ, 2019).

De acordo com esse levantamento, a Rede Municipal de Ensino assegura os Planos de Carreira para os (as) profissionais da educação básica por meio da Lei Complementar $n^{\circ} 029$, de 4 de janeiro de 2006. Essa Lei assegura e dispõe sobre o Plano de Cargos, Carreiras e Remuneração dos servidores do Magistério Municipal do Quadro Permanente da Prefeitura Municipal de Ponta Porã (PONTA PORÃ, 2019).

A efetividade do PME depende de investimentos da Prefeitura e possíveis aportes do Governo Estadual, da União e de outras fontes, e ainda deve se articular aos demais instrumentos de planejamento, sendo que os insumos necessários para a execução dos planos devem constar nos orçamentos da União e dos estados para que apoiem técnica e financeiramente os municípios ao longo da década (PONTA PORÃ, 2019).

Nessa linha, seguindo o breve panorama apresentado no relatório sobre as metas da educação em Ponta Porã/MS que traz o diagnóstico da realidade da educação no município, é oportuno realizar uma caminhada sobre os norteamentos nacionais para uma educação eficiente e humana. O Estado brasileiro no decorrer dos anos tem de certa forma impresso alguns esforços com objetivo de melhorar o currículo, a formação dos professores, o ambiente educativo, bem como as metodologias de ensino.

\section{Resultados E DiscuSSÃo}

É importante destacar que desafios se colocam diante da formação docente, articulado a esse pressuposto a necessidade da real aplicação das políticas públicas para que, assim, possam garantir a formação dos professores, pois a partir de uma formação de qualidade é possível melhorar a qualidade do ensino. 
Em síntese, a educação é um processo social que se desenvolve ao longo da vida, pois a função do docente na educação básica e na realização do trabalho pedagógico requer uma formação inicial juntamente com a formação científica e que as políticas públicas assegurem a formação ao longo da prática profissional, uma vez que enquanto não houver uma formação inicial e continuada para a carreira docente, que seja satisfatória e abrangente a todos os profissionais do ensino, não será possível ter uma educação pública de qualidade.

Diante disso, o PME atual representa um avanço em relação ao anterior no que tange à proposição de formação continuada dos professores em Ponta Porã e está alinhado com PNE e com o PEE.

Concluiu-se, portanto, que o PME é uma ferramenta importante para nortear a gestão educacional de um município, pois permite verificar as ações e as estratégias mais eficazes e emergentes que deverão constar no planejamento estratégico educacional para uma educação que se pretende construir nos próximos anos.

\section{CONSIDERAÇÕES FINAIS}

Pesquisar a formação continuada e seus efeitos no cotidiano escolar proporcionou um olhar aprofundado, provocando reflexão e análise sobre esse processo na formação de professores e os impactos na prática pedagógica escolar. Em virtude deste estudo, tornou-se fundamental compreender alguns aspectos que envolvem a formação continuada, tendo como base os documentos oficiais que respaldam a educação no município de Ponta Porã.

É evidente que a formação continuada de professores necessita mais do que espaço em um documento. Ela precisa ser executada, requer investimento e alvos bem definidos e compromisso político dos profissionais da educação, assumindo a prática docente com vistas à transformação social, de acordo com a base teórica constante nas diretrizes educacionais.

Diante do exposto e tendo ciência dos números apresentados, faz-se necessário destacar que nos documentos analisados pode-se verificar que a SEME de Ponta Porã procura ofertar cursos de formação continuada com o intuito de colaborar com esse aperfeiçoamento profissional, mesmo que não atendam tal demanda, diante das necessidades apontadas pelos professores em questão.

Em síntese, embora a criação desses documentos norteadores tenha se tornado uma significativa contribuição para um avanço na educação no Brasil, é importante ressaltar que diversos desafios ainda precisam ser vencidos para conquistar uma educação pública de qualidade. 


\section{REFERÊNCIAS}

AMORIM, Milene Dias. A qualidade da Educação Básica no PDE: uma análise a partir do plano de ações articuladas. 2011. 182 f. Dissertação (Mestrado em Educação, na área História, Políticas e Gestão da Educação) - Programa de Pós-Graduação em Educação, Faculdade de Educação, Universidade Federal da Grande Dourados, Dourados, 2011. Disponível em: https://repositorio.ufgd.edu.br/jspui/bitstream/prefix/94/1/MileneDiasAmorim.pdf.Acesso em: 6 ago. 2021.

BOGDAN, Robert; BIKLEN, Sari Knopp. Investigação Qualitativa em Educação: uma introdução à teoria e aos métodos. Porto, Portugal: Porto Editora, 1994.

BRASIL. Lei no 9.394, de 20 de dezembro de 1996. Estabelece as diretrizes e bases da educação nacional. Disponível em: http://www.planalto.gov.br/ccivil_03/leis/19394.htm. Acesso em: 20 mai. 2021.

BRASIL. Lei n⿳ 10.172, de 9 de janeiro de 2001. Aprova o Plano Nacional de Educação e dá outras providências. Disponível em: http://www.planalto.gov.br/ccivil_03/leis/leis_2001/110172.htm. Acesso em: 20 jul. 2021.

BRASIL. Lei $\mathbf{n}^{\mathbf{0}}$ 10.639, de 9 de janeiro de 2003. Altera a Lei ${ }^{\circ} 9.394$, de 20 de dezembro de 1996, que estabelece as diretrizes e bases da educação nacional, para incluir no currículo oficial da Rede de Ensino a obrigatoriedade da temática "História e Cultura Afro-Brasileira", e dá outras providências. Disponível em:

https://www.planalto.gov.br/ccivil_03/leis/2003/110.639.htm. Acesso em: 15 mai. 2021.

BRASIL. Decreto $\mathbf{n}^{\mathbf{0}}$ 6.094, de 24 de abril de 2007. Dispõe sobre a implementação do Plano de Metas Compromisso Todos pela Educação, pela União Federal, em regime de colaboração com Municípios, Distrito Federal e Estados, e a participação das famílias e da comunidade, mediante programas e ações de assistência técnica e financeira, visando a mobilização social pela melhoria da qualidade da educação básica. Disponível em:

http://www.planalto.gov.br/ccivil_03/_ato2007-2010/2007/decreto/d6094.htm. Acesso em: 18 mai. 2021.

BRASIL. Decreto-Lei no 22/2014, de 11 de fevereiro de 2014. Estabelece o regime jurídico da formação contínua de professores e define o respectivo sistema de coordenação, administração e apoio. Diário da República, $1^{a}$ série, $n^{0} 29$. Disponível em: https://data.dre.pt/eli/dec-lei/22/2014/02/11/p/dre/pt/html. Acesso em: 30 mai. 2021.

BRASIL. Plano Estadual de Educação de Mato Grosso do Sul (PEE-MS), 2014. Disponível em: http://pee.sistemas.sed.ms.gov.br/Arquivos/TEXTO BASE PEE-MS.pdf. Acesso em: 5 ago. 2021.

BRASIL. Lei no 13.005, de 25 de junho de 2014. Aprova o Plano Nacional de Educação PNE e dá outras providências. Disponível em: http://www.planalto.gov.br/ccivil_03/_ato2011-2014/2014/lei/113005.htm. Acesso em: 30 mai. 2021.

BRASIL. Constituição da República do Brasil de 1988. Brasília, DF: Presidente da República, 2016. Disponível em: 
http://www.planalto.gov.br/ccivil_03/Constituição/Constituição.htm. Acesso em: 18 mai. 2021.

BRASIL. LDB - Lei de diretrizes e bases da educação nacional. Brasília: Senado Federal, Secretaria de Editoração e Publicações, Coordenação de Edições Técnicas, 2017. Disponível em:

https://www2.senado.leg.br/bdsf/bitstream/handle/id/529732/lei_de_diretrizes_e_bases_1ed.p df. Acesso em: 20 mai. 2021.

BRASIL. Decreto no 10.195, de 30 de dezembro de 2019. Aprova a Estrutura Regimental e o Quadro Demonstrativo dos Cargos em Comissão e das Funções de Confiança do Ministério da Educação e remaneja e transforma cargos em comissão e funções de confiança. Disponível em: http://www.planalto.gov.br/ccivil 03/ ato2019-2022/2019/decreto/D10195.htm. Acesso em: 1 ago. 2021.

FREIRE, Madalena. A Formação Permanente. In: FREIRE, Paulo: Trabalho,Comentário, Reflexão. Petrópolis: Vozes, 1991.

IMBERNÓN, Francisco. A Formação continuada de professores. Porto Alegre: Artmed, São Paulo: Cortez, 2010.

IMBERNÓN, Francisco. Formação docente e profissional: formar-se para a mudança e a incerteza. 9. ed. São Paulo: Cortez, 2011.

IMBERNÓN, Francisco. Qualidade do ensino e formação do professorado: uma mudança necessária. Tradutor: Silvana Cobucci Leite. São Paulo: Cortez, 2016.

LIBÂNEO, José Carlos. Organização e gestão da escola: teoria e prática. 5. ed. rev. e ampl. Goiânia: Editora Alternativa, 2004.

LUDKE, Menga; ANDRÉ, Marli. Pesquisa em Educação: Abordagens Qualitativas. São Paulo: EPU, 1986.

MEC; SASE. Ministério da Educação; Secretaria de Articulação com os Sistemas de Ensino. O Plano Municipal de Educação: Caderno de Orientações. 2014. Disponível em: http://pne.mec.gov.br/images/pdf/pne_pme_caderno_de_orientacoes.pdf. Acesso em: 29 mai. 2021.

O OBSERVATÓRIO DO PNE. Acompanhe as 20 Metas do PNE. Disponível em: https://www.observatoriodopne.org.br/metas. Acesso em: 29 mai. 2021.

PONTA PORÃ. Lei Complementar no 029, de 4 de janeiro de 2006. Dispõe sobre o Plano de Cargos, Carreiras e Remuneração dos servidores do Magistério Municipal do Quadro Permanente da Prefeitura Municipal de Ponta Porã, Estado de Mato Grosso do Sul, e dá outras providências. Disponível em:

https://camarapontapora.ms.gov.br/public/pdf/e07ddfa4e2f21abc2b6d40dde56e3e201567704517.pdf. Acesso em: 2 jul. 2021. 
PONTA PORÃ. Lei no 4.100, de 2 de junho de 2015. Aprova o Plano Municipal de Educação de Ponta Porã-MS e dá outras providências. Poder Executivo, 2015. Disponível em: http://www.pontapora.ms.gov.br/leis/37.pdf. Acesso em: 22 mai. 2021.

PRADA, Luis Eduardo Alvarado. Dever e direito: formação continuada de professores. RPD -Revista Profissão Docente, Uberaba, v. 7,n. 16, p. 110-123, ago./dez. 2007.

SAVIANI, Dermeval. Escola e democracia. 41. ed. Campinas: Autores Associados, 2010.

SAVIANI, Dermeval. Da Nova LDB ao FUNDEB: por uma outra política educacional. 4. ed. Campinas: Autores Associados, 2011.

SEVERINO, Antônio Joaquim. Metodologia do trabalho científico.23. ed. São Paulo: Cortez, 2007. 